\title{
Research on the International Brand Strategy of Agricultural Products
}

\author{
Ningning Yan \\ School of Business Administration, Jingdezhen Ceramic Institute, Jiangxi Province, China \\ Isemail2008@163.com
}

Keywords: Agricultural products brand; Brand internationalization; International strategy; Strategic decision-making; Strategic rationale

\begin{abstract}
The current market competition has from the pure product competition to brand competition, brand competition from domestic to international. However, the road of the agricultural products brand international has been a lot of confusion and misconceptions. This paper discusses meaning and necessity about the internationalization strategy of agricultural products brand; analysis of agricultural brand internationalization strategy game equilibrium decision premise; studied dimension on agricultural products brand internationalization strategic decision rationality; international brand of agricultural products rationality and brand asset value correlations were the focus of exploration. Studies show that only meets the requirement of reasonableness, agricultural products enterprises brand internationalization strategic decision to implement it.
\end{abstract}

\section{Introduction}

The strategy of international brand of agricultural products is the globalization of the brand of agricultural products. It's mainly refers to the international market, the brand packaging and marketing of agricultural products, through the appropriate way to achieve an extension of expansion, which is a brand management strategy. Through this strategy, it can be unified and standardized, and it can bring economic benefits to producers and operators, and ensure the low cost of operation. We can understand the connotation of the concept of agricultural products brand internationalization from the following aspects:

First of all, the internationalization of agricultural products brand is a regional concept, but also a historical concept. With the formation of global integration of economy and trade, agricultural product brand will realize from local market to international market effective extension and expansion. Of course, this should also is a gradual and long process, not overnight of. Agricultural enterprises through long-term efforts, through hard work to promote the realization of the internationalization of the goal [1]. At the same time, if only by virtue of the enterprise its efforts that are unlikely to realize the internationalization of the brand, the corresponding more need a good political, economic and other aspects of a common form of external environment, so as to achieve the development of resistance is minimized. In addition, the international brand of agricultural products should be a long-term increase in sales and economic efficiency of the strategy to deal with.

Secondly, the international brand of agricultural products in a certain extent and the concept of transnational business concept is similar, there are links between the two, but also different. In the world market, the internationalization of agricultural products is mainly through a unified brand and unified marketing to achieve a unified market expansion. Relatively speaking, the transnational operation of agricultural products brand is mainly two between the organic combination of strategic market development, making use of the brand and marketing, and the market here is different, not without difference unified market. The international operation and transnational management in the marketing objectives also exist and show the root of the difference between the natures.

Third, the internationalization of agricultural products brand in a certain extent to showing a uniform product quality, showing a lasting image of enterprise, is the manufacturing and agricultural products processing enterprises in common consumption based on global consumers to make product quality commitment, to provide consumers with more excellent service. At the same time, in the 
market development and extension of the process more focus on technological innovation. Only in this way can we get the recognition of the international brand of agricultural products.

Fourth, the form of international brand of agricultural products is different. From lower to the top respectively for product sales, brand output and capital output (in order to achieve the expansion of the brand and the brand extension of regional investment plant), intangible assets output (in order to achieve brand expansion and signing a trademark use license contract and other forms). From the current global economic development, we know that many developed countries to achieve the internationalization of agricultural products brand from the lowest to the most advanced transition. On the whole, the business risk of the brand output is the smallest, and its return is the highest, which is the most ideal way [2].

Fifth, the international brand of agricultural products can show a high degree of responsibility of the corporate image. And this is also the enterprise strategic vision and internal operation system of organic coordination to achieve. Generally speaking, in the global scope, through various means to achieve effective organization and coordination of resources, will be able to promote the success of the brand internationalization. Today, the economic globalization has become a kind of inevitable trend, lots of famous brands are within the scope of global procurement, one of the corresponding research and development on the global market, which is the main feature. Implementation of the international expansion of the brand of agricultural products, must be able to guarantee its core brand value does not change. Under this premise to take specific economic activity, through this a series of economic activities to achieve the brand competitiveness in the international market and share and expand the brand of area coverage. At present, it is necessary to make brand of agricultural products in a field of business, maximize the grasp of the existing resources, then on the life cycle of agricultural products were specific, focusing on, in order to achieve the maximization of brand life extended to achieve the maximization of the charm of the brand value, the brand in the international market to achieve maximum extension, which is a difficult problem, but also is a strategic issues.

\section{The Game Analysis on the Premise of the International Strategic Decision of the Agricultural Product Brand}

Today, the global economic integration and regional economic integration has been formed. In this situation, China's agricultural production is relatively stable, China's agricultural trade has a certain development, the overall trend of continued growth. These, to a certain extent, promote the adjustment and improvement of agricultural structure. But there are also many problems, it is worth our attention. Such as many of the export of agricultural products are land intensive products, etc.. In recent years, China's agricultural export trade by virtue of the price and quantity of a certain degree of increase; to a certain extent, stimulate and ensure the development of China's agricultural export trade and sustained and rapid growth. At the same time, the technical barriers to the developed countries, to a certain extent, also to China's agricultural trade has played a corresponding limit. At present, agricultural internationalization trend is more and more obvious. Through analysis, we know that, with the advent of economic integration, making international competition is no longer the traditional price, quality and scale of competition, but gradually through the brand competition to present. We also know that in the current implementation of the internationalization of agricultural products must meet the corresponding requirements of the corresponding preconditions, that is, to maximize the benefits and profits of enterprises. In this way, for enterprises, it is required to consider whether the implementation of brand internationalization. Therefore, the current pendulum in the industry and academia, a major real problem is whether it should go out and how to go out of the problem [3].

It was Akerlof's theory that it was awarded the Nobel Prize in economics. Through its proposed "lemon" principle, so that people realize the information asymmetry caused by the low efficiency of the market, and even the phenomenon of shrinking and other phenomena. Here we analyze the relevant problems by using the reverse selection model, and finally, there may be a number of different equilibrium results. In this way, we can use the market type as a standard to judge the efficiency and 
significance of different equilibria. Generally speaking, the market equilibrium is mainly divided into four types, which is based on the efficiency difference [4]. First of all, we must first make clear the four types of market equilibrium, and the classification of its types can be applied to the model and other market transactions and other related issues.

(1) Market Failure

If the quality of the products on the market, whether it is the quality of its products, can not be sold in the market, so that the product market will gradually shrink until paralysis. If the underlying trading interests are fully present, this is what we are saying, "the market is totally failed."'.

(2) The Market Is Completely Successful

If only the high quality products on the market, then for the production of low quality products for enterprises, they will not put their products into the market. This creates a high quality products flooded the market, when consumers buy all the products on the market, the business has achieved the maximum transaction benefits, this situation is here to say that the market is completely successful".

(3) The Success of the Market Segment

If all products produced by the enterprise are put into the market, and all products are purchased by consumers, the kind of situation is that the market is part of the success of the market ". Because, in this case the transaction has a part of the "bad", that is, consumers in the purchase of low quality products in the process also suffered a certain loss.

Four types of market, market failure and success belong to the pooling equilibrium, that different types of enterprises, have adopted the same behavior of market equilibrium; the corresponding market success belongs to the separating equilibrium, that is to say, different types of enterprises, taking different behavior of market equilibrium. Market close to failure and these two types of pure strategy equilibrium is different, mainly belong to a mixed strategy equilibrium [4].

After the comparative analysis of the model and the equilibrium, we recognize that, if businesses and consumers in asymmetric information on the quality of the products, and the lack of corresponding signal mechanism, then the market will appear adverse selection even completely disappear. In this case, if you want to achieve success in the market need to disguise the cost is large enough, the conditions are very harsh, the possibility of achieving very small. What we are most willing to accept is that the market is a complete success. However, the relatively inefficient market equilibrium will under the asymmetric information is proposed, the implementation of enterprise brand strategy an important prerequisite is: product quality is low in disguise into high quality products obtained income is greater than its disguise cost, then firms will to do so. And consumers of product quality is fuzzy, cannot be judged; in the market of low quality products, the more easily lead to market failure, and consumers need a signal, so as to understand the quality of products. In fact, the perfect symmetry of information, can effectively solve the problem of low efficiency of the market caused by asymmetric information, which is a fundamental method. In the information age, consumers have more efficient means to obtain information, so that it can effectively reduce some uncertainty, can reduce operating risk. However, to a certain extent, it will bring about too high transaction costs, thereby reducing the consumer surplus. For enterprises should choose useful information, so as to eliminate information asymmetry.

To raise the cost of camouflage is a relatively realistic and effective way. This can allow enterprises to conduct fraud cannot reap the benefits. At the same time, by the government to develop and product quality related national standards and industry standards formulated and effective implementation of relevant laws and regulations to reduce the number and proportion of low quality products on the market, so that the majority of consumers to participate in the market, with the government and the people together to carry out the counterfeiting activities, and long-term implementation. Of course, this will result in excessive regulatory costs or cause the rise in the market transaction costs and other phenomena. Through the implementation of these methods, can effectively change the external conditions of the market, enterprises can implement the mechanism of improving the efficiency of the market. In short, only to meet the requirements of rationality, the brand internationalization strategy of agricultural enterprises can be implemented. 


\section{The Dimensions of the Rationality of the Strategic Decision of the International Brand of Agricultural Products}

Dimensions of the rationality of agricultural products brand internationalization strategic decision is reasonable and realistic social comments three aspects of rationality and cultural rationality, practical rationality refers to meet the current stakeholders form calculation. At present, compared with developed countries, China's agricultural science and technology has a big gap, scientific and technological innovation ability is low, and therefore cannot adapt to the development of agricultural products market. We should have a correct understanding of China's science and technology innovation and independent innovation ability is relatively weak, so we should study hard core technology, scientific research institutions play the role of agricultural products, independent innovation, research more scientific and technological achievements, reduce the important technical equipment import pressure; we should also try to improve and perfect the agricultural science and technology the innovation system of agricultural products, increase scientific and technological innovation investment, deepen the transformation speed of scientific and technological achievements into productive forces and timely; the government should guide farmers to improve the technology level and overall quality, promotion of new technology and new achievements, absorb the transformation ability, increase the knowledge of agricultural science and technology promotion and popularization. At present, we should seize the opportunity, the courage to face the challenge, grasp the development trend of agricultural products market in a timely manner, through scientific and technological innovation and independent innovation to achieve the great development of agricultural technology [5].

Cultural rationality is the most powerful and reasonable source. For example, the U.S. investment in advertising is the largest in all countries. And the United States agricultural enterprises also through advertising to enhance its brand image, and ultimately achieve market share. In the United States, the publicity of the famous brand in advertising is between 100 million and 1 billion dollars. After making careful planning, the United States agricultural products in order to enter the international market. For example, the United States Sunkist orange reality through television advertising, signs, light boxes, and so on are corresponding propaganda, on the basis of before entering the Chinese market, then on the basis of the actual sales to carry out a series of promotional activities. Through its unique advertising planning, effective public relations, and ultimately achieve sales results.

\section{The Rationality of the Internationalization Strategy of Agricultural Products Brand and the Correlation Analysis of the Value of Brand Equity}

First of all, the rationality of the impact of rational consumer awareness. Generally speaking, the rational strategic behavior of enterprises has a great influence on the consumers' regulation level, standard level and cognitive level. Rational strategy is used to get a positive correlation between the quality of the rational strategy and the reasonable sexual knowledge. Enterprises should from the regulation level and strict demands on themselves to follow the target country to develop the corresponding laws, regulations and the technical guidelines and, so that we can get the perception of higher consumer rationality; the enterprise should from the standard layer area very abide by the target country is some industry and ethics, in order to obtain higher perception of legitimacy; enterprises should also from the cognitive perspective to understand and comply with the cultural and social norms of the target consumer. A brand is formed in the long-term sales of brand culture can allow consumers to have a deep impression on the, feel good, so that we can enhance the added value of products, consumers can from the business outlook, values and the aesthetic values generated in a psychological meet, the realization of the utility, and realize the brand value. Generally speaking, brand in order to achieve long-term vitality must be attached to the culture, showing a unique brand of spiritual, for consumers to provide corresponding function and the emotional value, meet the needs of consumers purchase and use demand, let consumer produce happy, care and emotional value demand. From the perspective of the international market, the brand of agricultural products in France is very unique, but 
also the most successful. At the same time, the production enterprise of champagne can also observe the traditional brewing process, which makes the champagne in the international market reputation [6].

Second, the rationality of the impact on brand equity. It can be said that the rationality of the enterprise strategy will greatly from the regulatory level, the standard level and the cognitive level and other aspects of the impact of consumer brand equity to the corresponding evaluation. Rational behavior is good or bad, can decide the enterprise to obtain the good and bad of consumer evaluation. Taking apple as an example, the Shaanxi apple in our country is superior to the European apple in the individual quality. But apple in Shaanxi province in the production, processing, packaging, storage and transportation aspects behind in Europe and in Europe relative to the sales of the industry chain is not perfect, on the commercialization of apple processing rate is relatively low, the apple storage technology, and packaging are relatively backward, thus causing the added value of the products is relatively low. At the same time, the European national government also uses the financial, science and technology and trade policies and measures to support enterprises to gradually become a brand industry, to promote its brand to a great extent, and so on. These policies or measures can affect the value of brand equity to a certain extent, promote the value of brand equity.

\section{Summary}

On the road of the internationalization strategy of China's agricultural products enterprises, it is an effective means to improve the value of brand equity through rationality. Whether regulation, regulation, or the rational decision of cognitive level can help us to improve the evaluation of the brand of agricultural products. Agricultural products enterprise brand internationalization strategy implementation is a systematic activity and follow the objective laws and regulations, create a law-abiding corporate image can influence consumers to the brand objective evaluation. Therefore, China's agricultural enterprises in the brand internationalization strategy activities should also focus on practical rationality, social consensus and cultural rationality, and ultimately create a successful international brand of agricultural products.

\section{References}

[1] Hyung Sup Choi.Science policy mechanism and technology development strategy in the developing countries. Technological Forecasting \&Social Change, 1988, 33: 279-292.

[2] Akerlof, G. A. The Market for "Lemons": Quality Uncertainty and the Market Mechanism.The Quarterly Journal of Economics, 1970, 84: 488-500.

[3] Carayannis E G, Popescu D,Sipp C,Stewart M Technological learning for entrepreneurial development (TL4ED) in the knowledge economy (KE):Case studies and lessons learned. Technovation, 2006, 26:419-443.

[4] Damanpour F.Organizational Innovation:a Medi-analysis of Effects of Determinants and Moderators. Academy of Management Journal, 1991, 34 (3): 555-590.

[5] Hinkin, T. R. A review of scale development practices in the study of organizations. Journal of Management, 1995, 23: 967-988.

[6] Garud, R, Nayyar, P.R. Transformative capacity: Continual structuring by intertemporal technology transfer. Strategic Management Journal, 1994, 15(5): 365-386. 